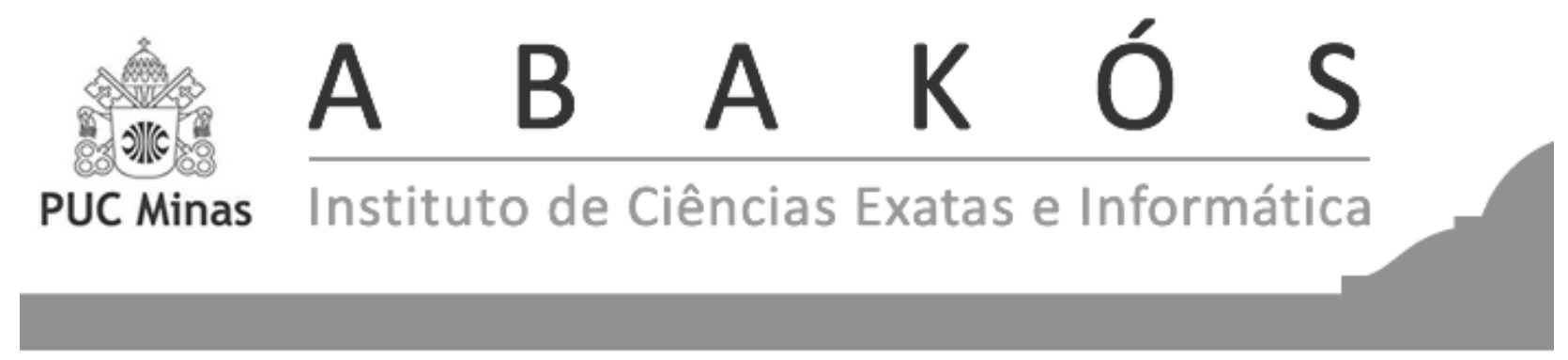

\title{
Uma breve introdução às filosofias da lógica e da matemática de Bertrand Russell: conceitos e inferências a partir do número*
} A brief introduction to Bertrand Russell's philosophies of logic and mathematics: concepts and inferences from the number

\author{
Raquel Anna Sapunaru ${ }^{1}$ \\ Douglas Frederico Guimarães Santiago ${ }^{2}$ \\ Mateus Martins Vieira ${ }^{3}$
}

\begin{abstract}
Resumo
O artigo explora algumas ideias de Bertrand Russell, expostas no seu livro Introdução à Filosofia da Matemática, capítulos 1 e 2. Essas ideias são fundamentais para o entendimento de sua proposta matemática. Russell, nesses capítulos, trata basicamente dos números: o que são, como estão organizados e como esta organização funciona do ponto de vista da lógica e da Filosofia da Matemática. Em linhas gerais, o artigo se propõe a introduzir alguns conceitos pertinentes à lógica e à Filosofia da Matemática no entendimento de Russell e é direcionado ao público não especializado.
\end{abstract}

Palavras-chave: Russell. Número. Filosofia da Matemática. Lógica. Conceitos.

\footnotetext{
* Submetido em 10/03/2014 - Aceito em 05/09/2014

${ }^{1}$ Professora Doutora de Filosofia da Ciência - Instituto de Ciência e Tecnologia (ICT) da Universidade Federal dos Vales do Jequitinhonha e Mucuri (UFVJM), Brasil - raquel.sapunaru@ict.ufvjm.edu.br

${ }^{2}$ Professor Doutor de Matemática - Instituto de Ciência e Tecnologia (ICT) da Universidade Federal dos Vales do Jequitinhonha e Mucuri (UFVJM), Brasil - douglas.santiago@ict.ufvjm.edu.br

${ }^{3}$ Graduando de Engenharia Química - Instituto de Ciência e Tecnologia (ICT) da Universidade Federal dos Vales do Jequitinhonha e Mucuri (UFVJM), Brasil - mateusmartins.mv@ gmail.com
} 


\begin{abstract}
This paper explores some of Bertrand Russell ideas, exhibited in his book "Introduction to the Philosophy of Mathematics", Chapters 1 and 2. Those ideas are fundamental to understanding his mathematical proposal. In these chapters Russell deals basically with the numbers: what are they, how are they organized and how do this organization works from the point of view of logic and Philosophy of Mathematics. In general, this paper proposes to introduce some relevant concepts to Logic and Philosophy of Mathematics in the Russell's mind and it is directed to the non-specialist audience.
\end{abstract}

Keywords: Russell. Number. Philosophy of Mathematics. Logic. Concepts. 
"A matemática não é apenas outra linguagem: é uma linguagem mais o raciocínio; é uma linguagem mais a lógica; é um instrumento para raciocinar."

(Richard Feynman)

\section{INTRODUÇÃO}

Britânico, nascido em 18 de maio de 1872, Bertrand Russell, contribuiu de forma marcante para o desenvolvimento dos fundamentos da Matemática e da lógica formal contemporânea. Suas contribuições matemáticas envolvem a descoberta do paradoxo de Russell, sua defesa do Logicismo e sua teoria dos tipos, entre outras. Coube a Bertrand Russell a tarefa de elaborar e influenciar de modo definitivo o pensamento do homem do século $\mathrm{XX}$, principalmente no que concerne às teses pertinentes ao domínio da Matemática. Dentre essas teses, destacam-se a tese logicista, ou da lógica simbólica. Grosso modo, para Russell, todas as verdades matemáticas, e não apenas as da aritmética, como pensava Frege, poderiam ser deduzidas a partir de umas poucas verdades lógicas. Deste modo, todos os conceitos matemáticos seriam reduzidos a uns poucos conceitos lógicos primitivos e, as obscuridades que cercavam o cálculo, como, por exemplo, as regras de derivação que como fora proposto por Leibniz, funcionavam sem o uso de demonstrações mais formais, seriam clarificadas pelo conhecimento profundo dos números e de sua lógica (RUSSELL, 2001, p.407). Russell deixou uma obra incomparavelmente grande, pois, "reza a lenda" que o filósofo escrevia 10 páginas por dia!

Em um contexto filosófico-lógico-matemático-histórico, Russell desenvolveu sua teoria dos números, por assim dizer, e a sacramentou juntamente com Alfred Whitehead, em 1903, no Principia Mathematica. Esta monumental obra, publicada no início do século XX, é composta de três volumes que versam sobre os fundamentos da Matemática como um todo. O Principia Mathematica é considerado pelos especialistas, matemáticos e filósofos, como um dos mais importantes trabalhos sobre a interdisciplinaridade entre a Matemática, a lógica e a Filosofia. Devido à sua característica interdisciplinar, o Principia Mathematica pretendia concluir todas as verdades matemáticas, de todas as áreas da Matemática, baseando-se num rol extremamente bem definido de axiomas e regras de dedução, usando uma linguagem desenvolvida pelos autores especialmente para esse fim. Todos esses predicados fizeram do Principia Mathematica uma obra extremamente difícil de ser lida e compreendida, até mesmo por matemáticos e/ou filósofos experientes (BOYER, 2009, p.424-427; RUSSELL, 2001, p.408-410). Sob essa luz, Russell, em iniciativa solo, escreveu, em 1918, o livro Introdução à Filosofia da Matemática. Este livro ficou conhecido entre os estudiosos como a versão simplificada do Principia Mathematica $^{1}$ (RUSSELL, 2001, p.410).

\footnotetext{
${ }^{1}$ A título de ilustração, a Filosofia da Matemática é um segmento da Filosofia que tem o objetivo de responder perguntas específicas, a saber: 1) Qual a origem dos objetos matemáticos? 2) Qual o relacionamento entre lógica e Matemática? 3) Qual a influência da experiência sobre as abstrações matemáticas? 4) Como definir o conceito de beleza e elegância que matemáticos associam às demonstrações? 5) Que raciocínios matemáticos podem ser considerados pensamentos sintéticos à priori no contexto da Filosofia kantiana? (Raquel Anna Sapunaru em comunicação oral)
} 
Em parte incompreendido por seus contemporâneos, tanto filósofos como matemáticos, Frege prosseguiu publicando. Em 1884, este autor publicou Die Grundlagen der Arithmetik, conhecido como Grundlagen, obra-prima filosófica que sofreu duras críticas por parte dos matemáticos de sua época. Em 1903, mesmo ano da publicação do Principia Mathematica de Russell, Frege publicou o segundo volume do Grundgesetze der Arithmetik. Apesar da natureza extraordinária das descobertas de Frege, sua obra permaneceu na obscuridade até 1903, quando Russell chamou atenção para a relevância dos escritos fregeanos. O grande contributo de Frege para a lógica matemática foi a criação de um sistema de representação simbólica, o Begriffsschrift, para representar formalmente a estrutura dos enunciados lógicos e suas relações, e a contribuição para a implementação do cálculo dos predicados (BURGET, 1977, p.356; GOMES, 2011, p.816-817).

A ligação entre Russell e Frege é forte e conturbada, mas neste artigo, não pretendemos explorá-la. Nosso intuito é simplesmente prover uma leitura inicial e fortemente conceitual da incrível obra de Russell, contando, sempre, com a não menos brilhante ajuda de Frege.

\section{A IDEIA LÓGICA DE RUSSELL}

A Matemática de modo geral, ou mesmo vista sob um aspecto particular, pode ter os seus estudos iniciados em sentidos opostos quando se trata de organizar e classificar os números. O mais comum é o construtivo, ou seja, a organização numérica possui uma complexidade escalar que cresce de forma gradual, dos inteiros para os fracionários, destes para os reais, daí para os complexos, da adição e multiplicação para a diferenciação e integração, e muito mais. A seu turno, o outro sentido avança para uma análise de abstração e de lógica ainda mais complexa. Em vez de indagar o que pode ser definido e deduzido daquilo que se admite como premissa, indaga-se quais ideias e princípios gerais ou postulados podem ser encontrados no ponto de partida (RUSSELL, 1966, p.9-10). Essa última forma representa a síntese dos trabalhos de Russel, que se preocupava em questionar os axiomas e postulados necessários para o desenvolvimento de uma teoria matemática, buscando, às vezes, por meio de um refinamento no entendimento do que se quer enxergar, reduzir o número de axiomas necessários, tornando alguns destes dedutíveis usando apenas recursos da lógica. Quando temos a interação de um conjunto de postulados e uma lógica, obtemos uma teoria matemática completa. Deste modo, o conjunto de postulados que encontra-se na base de uma teoria matemática, associado à lógica, origina as regras pelas quais esta base pode se expandir e, por exemplo, a estrutura algébrica dos números naturais se transformar na estrutura algébrica de um "corpo matemático" (LIMA, 2007, p. 4-6; GOMIDE, 2011, p. 996).

A título de ilustração, por "corpo matemático" entende-se um conjunto fechado F com duas operações binárias, adição (+) e multiplicação (.), que satisfazem os axiomas abaixo: 
a) Associatividade:
i) $a+(b+c)=(a+b)+c$
para todo $a, b, c \in F$
ii) $a .(b . c)=(a \cdot b) \cdot c$
para todo $a, b, c \in F$

b) Comutatividade:
i) $a+b=b+a$,
para todo $a, b \in F$
ii) $a \cdot b=b \cdot a$
para todo $a, b \in F$

c) Elemento Neutro:
i) $\exists 0 \in F ; a+0=0+a=a$
para todo $a \in F$
ii) $\exists 1 \in F ; a .1=1 . a=a$
para todo $a \in F$

d) Inverso:

i) Para todo $a \in F, \exists b \in F ; a+b=0$

ii) Para todo $a \in F, a \neq 0, \exists b \in F ; a \cdot b=1$

e) Distributividade:

i) $a \cdot(b+c)=a \cdot b+a . c, \forall a, b, c \in F$

Retomando a ideia de Russell, podemos considerar que há dois tipos de lógica, a saber: a simbólica e a matemática. Na lógica simbólica, representamos as várias relações entre proposições $^{2}$, classes ${ }^{3}$ entre outros. (EVES, 2004, p.670). Nas seções seguintes, abordaremos o significado destes e doutros conceitos ligados às Filosofias da lógica e da Matemática de Russell, mais acuradamente. Por hora, a exemplo deste filósofo e autor, utilizaremos uma analogia entre a lei do paralelogramo de Isaac Newton e a lógica simbólica. De acordo com o Corolário I de Newton, descrito no The Principia ${ }^{4}$ temos: "Um corpo, submetido a [duas] forças simultâneas, descreve a diagonal de um paralelogramo ao mesmo tempo em que ele descreveria os lados [deste paralelogramo] se as forças agissem separadamente." (NEWTON apud EVES, 2004, p. 671). Assim, pela lei do paralelogramo, duas forças que agem sobre um corpo geram uma força resultante, como na Figura $1^{5}$.

\footnotetext{
2“[...] oração de uma determinada linguagem examinada em relação às estimativas de sua veracidade (verdadeira, falsa) ou de sua modalidade (provável, possível, impossível, necessária, etc.).” (ROSENTAL; IUDIN, 1973, p.380) 3"Conjunto finito ou infinito, tomado como um todo, de objetos que se distinguem por um determinado corte [critério].” (ROSENTAL; IUDIN, 1973, p.67)

${ }^{4}$ Princípios Matemáticos da Filosofia Natural.

${ }^{5}$ Esta figura foi escaneada por Eves diretamente de The Principia e, por esta razão, apesar de representar uma grandeza vetorial, não foi definida deste modo por Newton.
} 
Figura 1 - Lei do Paralelogramo.

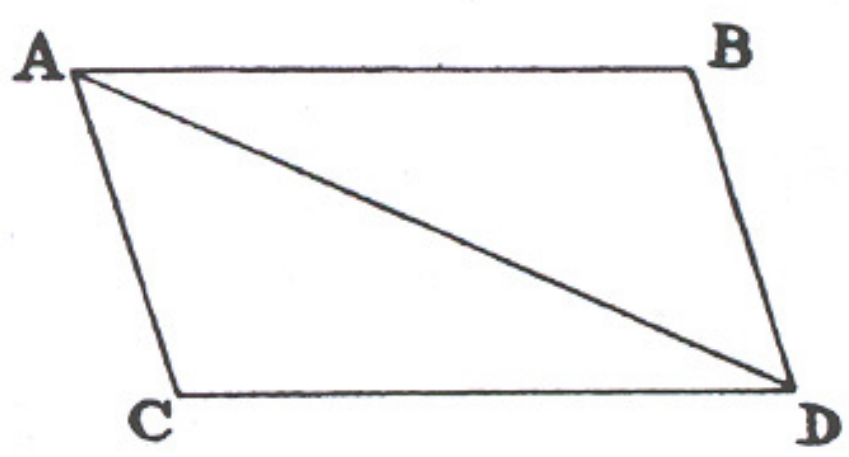

Fonte:(NEWTON apud EVES, 2004, p. 670)

De acordo com Russell, o mesmo ocorre com a lógica, associada a um conjunto de postulados: ao agirem conjuntamente geram a "Lógica Matemática" (EVES, 2004, p. 670). Por conseguinte, do mesmo modo que o telescópio e o microscópio ampliam o nosso campo de visão, necessitamos de dois tipos de instrumentos para ampliar a nossa capacidade, a saber: um para a Matemática em si e outro para seus fundamentos. Consequentemente, quando vamos falar em progressão dos números naturais, vamos partir do 0 e ir somando sempre 1 , de modo a compor um conjunto deste tipo: $0,1,2,3,4,5, \ldots, n, \ldots, n+1, \ldots$ (RUSSELL, 1966, p. 10-12). Observamos a partir do pensamento russelliano que há uma diferença entre a Matemática que, nesse exemplo, representa a operação de somar mais uma unidade aos números apresentados e o entendimento legítimo do que significam esses números em sequência. Nisto reside a diferença entre uma operação matemática e seus fundamentos. Em suma, o entendimento do "somar mais um" é intuitivo, inerente ao raciocínio humano, mas o entendimento do que é um conjunto ou uma série vai além dessa inerência.

Por essa razão, não podemos ignorar que somente uma civilização mais avançada poderia adotar a progressão mencionada anteriormente como ponto de partida para, posteriormente, explicar o conceito do corpo dos números Reais. De fato, pensando do lado da fundamentação matemática, foram necessários muitos e muitos séculos para a descoberta de que o número dois poderia ser qualquer coisa como um casal de faisões ou um par de dias. (RUSSELL, 1966, p. 18-25). Ambos os exemplos, caracterizam o número 2. O ato de relacionar números e objetos, ou qualquer quantidade de objetos a algum número, já foi uma tarefa muito complicada. Como apontamos anteriormente, não há um consenso quanto à definição de número. $\mathrm{O}$ conceito de 0 (zero) ou 1 (um) não tem o entendimento ou compreensão de seu significado. O conhecimento intuitivo comum diz que, a partir do 0 , podemos atingir qualquer outro número por adições repetidas de 1, mas isso não é totalmente verdadeiro. Exemplificando: se considerarmos o "Conjunto dos Números Reais", essa regra é falsa. Mesmo assim, esse pensamento encontrase tão enraizado em nossas mentes que chamamos o conjunto formado nesta modalidade de “Conjunto dos Números Naturais" (RUSSELL, 1966, p. 15-17).

Enquanto hipótese, a descoberta da Matemática pura tradicional, tendo como origem os números naturais, é razoavelmente recente, embora esta suspeita existisse desde a época 
de Pitágoras. A este pré-socrático é atribuída a descoberta da aritmetização da Matemática e a existência dos números irracionais, números que não podem ser medidos com a mesma medida. A natureza de partes incomensuráveis alude na escassez de sistemas numéricos frequentes, capazes de efetuar medidas de objetos geométricos ordinários, como o quadrado e o círculo. Destarte, se o comprimento do lado de um quadrado é $1 \mathrm{~cm}$, o número de centímetros do comprimento da diagonal é igual à raiz quadrada de 2. Na época de Pitágoras, a raiz quadrada de 2 pareceu não ser um número devido a sua incompatibilidade com a realidade observada (RUSSELL, 1966, p. 18-19). Porém, desde esta descoberta até a Matemática como a conhecemos, enquanto ciência exclusivamente racional, seus princípios foram sendo paulatinamente desenvolvidos. Primeiro, Giuseppe Peano reduziu a Matemática pura tradicional à teoria dos números naturais (PEANO apud KENNEDY, 2002, p. 40). Ele mostrou que a teoria dos números naturais podia ser deduzida de três conceitos e cinco proposições primitivas, além das da lógica pura. Desse modo, esses conceitos e proposições primitivas, se tornaram a base de toda Matemática pura tradicional (RUSSELL, 1966, p. 20-21). Os conceitos primitivos da aritmética de Peano são aparentemente simples. Existem o 0, o número e o sucessor. Assim, de acordo com Peano, o sucessor é o número seguinte na ordem natural. A seu turno, as cinco proposições primitivas adotadas por Peano são: 1) 0 é um número; 2) $\mathrm{O}$ sucessor de qualquer número é um número; 3) Não há dois números com um mesmo sucessor; 4) 0 não é sucessor de número algum; e; 5) Qualquer propriedade que pertença a 0, e também ao sucessor de todo o número que tenha essa propriedade, pertence a todos os números (RUSSELL, 1966, p. 13).

Posto, em primeiro lugar vamos discutir de que maneira os números naturais resultam desses três conceitos e dessas cinco proposições. De acordo com a primeira e a segunda proposição, podemos definir o número " 1 " como sucessor de " 0 ", " 2 " como sucessor de " 1 " e assim por diante. Logo, podemos continuar com essa sequência ad infinitum, pois de acordo com a terceira proposição, não podemos repetir nenhum número, pois dois números diferentes não podem ter o mesmo sucessor. Por fim, de acordo com a proposição “ 5 ”, todos os números estão nessa proposição (RUSSELL, 1966, p. 14), isto é, os números são os elementos da sequência de sucessores. Dessa maneira, forma-se o conjunto dos números naturais. Esta axiomatização feita por Peano para descrever os números naturais é interessante, mas se há de notar, tomando por base apenas estas regras, que elas podem descrever tanto o que entendemos por números naturais, como também outros conjuntos, em que o 0 (zero), o sucessor e os números podem ser vistos como entidades diferentes, como por exemplo, o conjunto dos números naturais pares e também as frações $1, \frac{1}{2}, \frac{1}{4}, \ldots$ Percebe-se então que para que sejam descritos os números naturais como os entendemos e, somente eles, precisamos de um refinamento lógico destes axiomas. Daí, Russell estabelece sua ideia de classe de números e, por número, entende-se a classe de números naturais. Nas palavras do próprio filósofo:

[... ] está claro que o número é uma forma de reunir certas coleções, isto é, as que têm um dado número de termos. Podemos imaginar todos as duplas em um grupo, todos os trios em outro e assim por diante. Dessa maneira obtemos vários agrupamentos de coleções, consistindo cada grupo de todas as coleções que têm um certo número de termos. Cada grupo é uma classe cujos membros 
são coleções, isto é, classes; assim, cada um é uma classe de classes. O grupo que consiste de duplas, por exemplo, é uma classe de classes: cada dupla é uma classe com dois membros, e o grupo inteiro de duplas é uma classe com um número infinito de membros, cada um dos quais é uma classe de dois membros. (RUSSELL, 1966, p. 21)

Seguimos explorando um pouco mais o conceito de número, numa perspectiva um pouco diferente da de Russell.

\section{UM POUCO MAIS DE NÚMEROS}

A resposta que consideramos mais correta sobre o que é um número foi dada por Gottlob Frege na obra Die Grundlagen der Arithmetik, na qual, segundo o próprio autor, um determinado número não é idêntico a uma coleção que o contenha (RUFINO, 2001, p. 130-131). Por exemplo, o número “ 3 ”, não é igual ao trio Artur, Joel e Rui, pois o número é algo que todas as coleções possuem, sendo que é o número que caracteriza certas coleções, classes ou conjuntos (RUFINO, 2001, p. 132-133). Vale aqui comentar brevemente o início do pensamento fregeano sobre o número. "O número um é uma coisa", diz no início do Grundlagen. Nela, Frege alega que o número 1 está entre as coisas, mas não indica que coisas seja estas (FREGE, 1980, p. 197). Disto, poderíamos deduzir que o número 1 poderia ser qualquer coisa, visto que cada pessoa o entenderia de um modo diferente, fazendo com que o mesmo não tenha conteúdo em comum. Assim, na equação $1+1=2$ podemos substituir 1 ambas as vezes pelo mesmo objeto ou podemos escolher um objeto para cada 1. Por essa razão, segundo Frege, os números naturais são vistos por muitos como algo muito simples (FREGE, 1980, p. 197-198). Dada a importância e influência da obra de Frege para a Matemática e, especialmente para a Filosofia da Matemática russelliana, pensamos ser interessante enriquecer esta discussão com um pouco mais da Filosofia da Matemática fregeana.

\section{UM POUCO DE FREGE}

Frege considera que a lógica e a Psicologia sejam separáveis em se tratando de definições e demonstrações. Explicando: a lógica formal normalmente é vista como algo separado do psicológico que a sustenta, pois $2+2$ são 4 independentemente dos objetos a eles atribuídos, por exemplo, bananas. A combinação de ingredientes psicológicos e lógicos, em uma mesma receita de ideia, é um traço característico da experiência associada ao formalismo. Assim, para Frege, mesmo que a demonstração formal não tenha nenhum tipo de lacunas, ela permanece ilusória (FREGE, 1980, p. 201). A partir deste pressuposto, Frege criou alguns princípios que consideramos, la crème de la crème do pensamento matemático, aplicáveis inclusive em 
situações da vida cotidiana. Os princípios fregeanos são:

1) Deve-se separar precisamente o psicológico do lógico, o subjetivo do objetivo.

2) Deve-se perguntar pelo significado das palavras no contexto da proposição e não, isoladamente.

3) Não se deve perder de vista a distinção entre conceito e objeto (FREGE, 1980, p.202).

Para Frege prosseguir com sua ideia, primeiramente, ele empregou o termo 'representação' no sentido psicológico e distinguiu estas representações dos conceitos e objetos. Já o segundo princípio tem uma interferência no primeiro, pois cada qual poderia interpretar uma palavra em um determinado contexto ao seu bel prazer. Quanto ao terceiro, o filósofo entendeu que não passa de uma mera ilusão pretender que seja possível converter um conceito em objeto sem alterá-lo (FREGE, 1980, p.202). Para reforçar seu ponto de vista, Frege escreveu um texto no qual ele dizia que a Matemática tinha se afastado dos rigores euclidianos. Por isso, a aritmética herdou uma forma mais frouxa do que a geometria. A descoberta da análise veio para reforçar a aritmética, pois, por um lado houve oposição a um tratamento rigoroso desta devido às dificuldades consideráveis e, por outro lado, os esforços despendidos para superá-las pareceram prometer pouca recompensa. Em seguida, ele percebeu que, para a Matemática, não basta uma convicção simplesmente moral, apoiada sobre muitas aplicações. Hoje, é mister a demonstração, até mesmo, para os casos mais simples (FREGE, 1980, p.202).

Esse caminho o conduziu para os conceitos de números e para as proposições mais simples, válidas somente para os números inteiros positivos. Daí, surgiram as bases que constituíram os conceitos mais fundamentais da aritmética. Originam-se, então, dois tipos de demonstrações, a saber: 1) quando, na dedução, esbarramos apenas em leis lógicas gerais e definições: a proposição é analítica e 2) quando é possível obter a demonstração sem lançar mão de verdades que não são da natureza lógica geral, mas que remetem a um domínio científico particular: a proposição é sintética. Em linhas gerais, as proposições analíticas são aquelas verdadeiras por definição e devido ao seu significado em si. A seu turno, proposições sintéticas são verdadeiras pelo significado pelo qual se relacionam com o mundo (FERREIRA, 2007, p. 14-15; RUSSELL, 2001, p. 343-344). De acordo com Immanuel Kant, uma proposição analítica é uma proposição cujo conceito do predicado está contido no conceito sujeito e uma proposição sintética é uma proposição cujo conceito do predicado não está contido no conceito do sujeito (FERREIRA, 2007, p.14-15; RUSSELL, 2001, p.343-344). Como exemplos de proposições analíticas, temos:

a) "Todos os felinos são mamíferos."

b) "Todos os triângulos têm três ângulos." 
Observa-se que, nessas proposições analíticas, o conceito do predicado está contido no conceito do sujeito, pois "ser felino" implica em "ser mamífero" e "ser triângulo" implica em "ter três ângulos".

Como exemplos de proposições sintéticas, vemos:

a) “Todos os celibatários são infelizes."

b) "Todas as criaturas com coração têm rins".

Já nas proposições sintéticas, o conceito do predicado não está contido no conceito do sujeito, visto que, não necessariamente, "ser celibatário" implica em "ser infeliz" ou "ter um coração" implica em "ter rins” (FERREIRA, 2007, p. 14-15; RUSSELL, 2001, p. 343-344). Em seguida, daremos prosseguimento a outros conceitos.

\section{MAIS HISTÓRIAS E CONCEITOS}

Segundo a filósofa americana Susan Haack, em seu livro Filosofia das lógicas, no século XIX, século das publicações de Frege e Russell, houve um grande crescimento no desenvolvimento e no estudo de sistemas lógicos, entendidos de dois modos distintos, a saber: do ponto de vista da Matemática formal e do ponto de vista da Filosofia da Matemática. No que tange ao formalismo matemático, destacam-se:

a) O desenvolvimento do aparato lógico padrão, isto é, a síntese dos cálculos de predicados ${ }^{6}$ com Frege, Russell e Whitehead.

b) $\mathrm{O}$ desenvolvimento de alguns cálculos como as lógicas modais ${ }^{7}$, lógicas polivalentes ${ }^{8}$ e lógicas intuicionistas ${ }^{9}$, ou seja, o desenvolvimento de cálculos "não clássicos".

Já sobre a Filosofia da Matemática, avançou-se nas seguintes direções, a saber:

a) No estudo filosófico da aplicação dos sistemas lógicos no argumento informal, na inter-

\footnotetext{
6"É uma ampliação do cálculo proposicional mediante a formalização das inferências que se baseiam na estrutura interna das proposições." (ROSENTAL; IUDIN, 1973, p. 55)

7 “Sistema lógico que formaliza relações como as de 'necessidade', 'realidade', 'possibilidade', 'casualidade', e suas negações.” (ROSENTAL; IUDIN, 1973, p. 281)

8 "Sistema lógico-formal cujas expressões admitem em sua interpretação mais de dois significados verdadeiros [...]" (ROSENTAL; IUDIN, 1973, p. 281)

9““...] corrente matemática fundada por L. E. J. Brouwer, inspirada nas ideias de L. Kronecker [...], para quem o conceito de número natural fora dado à intuição humana, afirmando que os números naturais foram feitos por Deus e os outros pelo homem."(ABBGNANO, 2003)
} 
pretação dos conectivos ${ }^{10}$ e dos operadores ${ }^{11}$ como os de verdade ${ }^{12}$ e verdade das linguagens formais e/ou formalizadas ${ }^{13}$.

b) No estudo dos objetivos e da capacidade de formalização por alguns que acreditam que a Filosofia das linguagens formais é importante (HAACK, 1998, p. 17-21).

De acordo com a autora, as lógicas "não clássicas”, isto é, aquelas que têm mais de dois valores de verdade ou que não descendem diretamente de Aristóteles, desenvolveram-se lado a lado com a lógica clássica. Deste modo, o desenvolvimento das áreas supracitadas são dependentes entre si. Por exemplo: mesmo que a lógica modal e a lógica polivalente sejam mais antigas, os seus desenvolvimentos formais e sistemáticos só ocorreram após a formalização dos cálculos "não modais" (HAACK, 1998, p. 133-136). Concomitantemente, as críticas filosóficas tiveram uma grande influência no desenvolvimento dos cálculos "não clássicos", como no caso das lógicas modais, da pretensão do condicional de representar a implicação ${ }^{14}$. Outrossim, novas questões filosóficas levantadas originalmente pelos cálculos clássicos tiveram um grande avanço graças às inovações formais, como as questões sobre a interpretação dos quantificadores e sua relação com termos singulares ${ }^{15}$ que surgiram de uma forma nova quando a inteligibilidade da lógica modal de predicados foi contestada (HAACK, 1998). Algumas vezes, os novos sistemas formais desafiaram as pressuposições aceitas sobre os objetivos e aspirações das lógicas formais, como a lógica da relevância que questiona além da adequação dos condicionais materiais. Esta lógica também questiona a concepção clássica de validade ${ }^{16}$. Já a lógica intuicionista deriva em parte de um desafio a presunção "logicista" da prioridade da lógica em relação à Matemática e às lógicas polivalentes, que afirmam que a formalização não precisa, necessariamente, corrigir ou evitar a vaguidade ${ }^{17}$ (HAACK, 1998).

10“Na lógica contemporânea, esse é o nome dado aos símbolos impróprios [...] que, combinados com uma ou mais constantes, formam ou produzem uma nova constante.” (ABBGNANO, 2003, p. 173)

11 “[...] um símbolo impróprio [...] que pode ser usado, juntamente com uma ou mais variáveis e com uma ou mais constantes ou formas para produzir uma nova constante ou forma." (ABBGNANO, 2003, p. 729)

12“Reflexo fiel, assertivo, da realidade no pensamento, reflexo comprovado, em última instância, mediante o critério da prática. " (ROSENTAL; IUDIN, 1973, p. 479)

13“Um dos conceitos fundamentais da semântica lógica; é uma pontuação do conceito aristotélico de verdade aplicado às proposições das linguagens formalizadas.” (ROSENTAL; IUDIN, 1973, p. 480)

14 “Operação lógica que forma uma proposição composta de duas proposições (por exemplo, p e q) por meio do nexo lógico Se p ... então q" (ROSENTAL; IUDIN, 1973, p. 236; HAACK, 1998, p. 133-136])

15 "Termo ou uma proposição que denota um único objeto [...]" (ABBGNANO, 2003, p. 903)

16“"Conformidade com regras de procedimento estabelecidas ou reconhecidas. Nesse sentido, diz-se que há validade na inferência que se conforme às regras da lógica, na lei que se conforme às regras constitucionais, na sentença que se conforme às leis, na ordem que seja dada pela pessoa a quem cabe dá-la e nas formas estabelecidas pela regra.“(ABBGNANO, 2003, p. 903)

17 “Diz-se que uma palavra (ou um conceito ou uma proposição) é vaga se o seu significado não for suficientemente determinado, de tal modo que haverá casos em que parecerá impossível decidir se ela é aplicável ou não" (ABBGNANO, 2003, p. 987). 


\section{CLASSES E EQUIPOTÊNCIA DE CLASSE}

Uma classe ou uma coleção pode ser definida de duas maneiras distintas. A primeira maneira de definir uma classe é por enumeração, quando dizemos "A coleção a que me refiro é a de Artur, Joel e Rui" e a segunda é a que menciona a definição que enumera. Esta, segundo Russel, é chamada de extensão, enquanto que aquela é chamada de intenção ou compreensão. Para Frege, entre os dois tipos de definições, a de compreensão é mais fundamental, pois a definição extensional pode ser sempre reduzida a uma definição compreensiva e a definição compreensiva frequentemente não pode, nem sequer teoricamente, ser reduzida a uma definição extensional (EVES, 2004, p. 24). Assim, Artur, Joel e Rui possuem uma certa propriedade que não é tida por mais ninguém em todo o universo, a saber: a de serem ou Artur, ou Joel ou Rui. Logo, podemos usar essa propriedade para dar uma definição por compreensão da classe que consiste de Artur, Joel e Rui. Podemos por exemplo, na tentativa de definir o conjunto por compreensão dizer que o conjunto é o conjunto dos elementos x, tais que x é Artur, ou x é Joel, ou x é Rui (EVES, 2004, p. 25).

Para ficar ainda mais claro, podemos notar que a enumeração não poderá ser sempre utilizada, por exemplo, não podemos contar todos os números naturais, ou seja, é impossível utilizar a enumeração com as classes infinitas (EVES, 2004, p. 25). Em primeiro lugar, os números formam, eles próprios, uma coleção infinita e não podem ser definidos por enumeração (EVES, 2004, p. 25). Em segundo lugar, as coleções que possuem um determinado número, por exemplo, são infinitas, ou seja, existem infinitas duplas, trios e assim por diante. Como queremos definir o número, também, vamos conceituar o infinito, visto que para definir o mesmo tem que ser por compreensão (EVES, 2004, p. 26). Para muitos, uma classe e uma característica que a define são praticamente a mesma coisa, no entanto, a diferença consiste no fato de haver apenas uma classe com um dado conjunto de membros, mas, há sempre muitas propriedades características diferentes pelas quais uma determinada classe pode ser definida. Assim sendo, um homem pode ser definido como bípedes sem penas ou como animais racionais (EVES, 2004, p. 27).

O agrupamento é uma classe de classes (EVES, 2004, p. 27). Portanto, para saber em qual agrupamento deve ficar cada coleção, temos que determinar quantos membros têm cada uma. Assim, é só colocar cada classe em um agrupamento de acordo com o número de membros. Consequentemente, concluímos que é necessário contar para saber quantos membros temos em uma coleção, mas, ela só pode ser utilizada quando trabalhamos com uma coleção finita, ou seja, não podemos utilizar a mesma para todos os casos (EVES, 2004, p. 28). Isto nos leva ao conceito de relação, sem o qual a Matemática não existiria. Suponhamos que existam, no mundo, a mesma quantidade de esposas e maridos. Neste caso, diríamos que existe uma relação de um para um. Diz-se que uma relação é de "um para um" quando, se " $x$ " tem essa relação com " $y$ ", nenhum outro " $x$ " tem a mesma relação com y, e "x" não tem a mesma relação com qualquer elemento “y” "diferente de "y" (EVES, 2004, p. 28). Quando somente a primeira 
relação é satisfeita, chamamos essa relação de "um para muitos", já quando apenas a segunda é satisfeita, chamamos de "muitos para um" (EVES, 2004, p. 28). Combinando as ideias de classe e relação, Russel diz que duas classes são equipotentes quando existe uma relação de "um para um" capaz de relacionar essas duas classes, como a relação de maridos e esposas (EVES, 2004, p. 28). A classe dos elementos que tem uma determinada relação com algo é chamada de domínio daquela relação, como os maridos são o domínio da relação de marido para esposa. Já a relação da esposa para o marido, é chamada de inversa. Utilizando essas definições, o autor chegou a seguinte conclusão: "Uma classe diz-se «equipotente» a outra quando há uma relação de um-para-um da qual uma das classes é o domínio e a outra é o domínio inverso" (EVES, 2004, p. 29). Desse ponto, Russell inferiu que toda classe é equipotente a si mesma. Se uma classe "a" é equipotente a uma classe "b", então "b" é equipotente a "a". Se "a" é equipotente a "b", e "b" é equipotente a "c", então "a" é equipotente a "c" (EVES, 2004, p. 29). A noção de equipolência não exige uma ordem, visto que o número de maridos é o mesmo que o número de esposas, sem termos de estabelecer uma ordem de precedência entre eles (EVES, 2004, p. 30). Essa noção também não exige que as classes equipotentes sejam finitas. Assim, se colocarmos, em um conjunto, os números naturais excluindo o " 0 " e as frações que têm " 1 " como numerador, podemos relacionar o 2 com o $\frac{1}{2}$, o 3 com o $\frac{1}{3}$, provando, assim, que as duas classes são equipotentes, sem que se precise contar a quantidade de elementos existentes em cada classe, o que seria impossível.

\section{CONCLUSÃO}

Retomando brevemente o cerne de nossa discussão, isto é, quais são os principais conceitos/ideias pertinentes à Filosofia da Matemática e à lógica na visão de Russell, levantamos os seguintes pontos, a saber:

1) Um número natural é o conjunto de todos os conjuntos com a mesma quantidade de elementos.

2) Os axiomas de Peano, apesar de descreverem perfeitamente bem os números naturais, não se limitam somente a estes, deixando espaço para imaginarmos outros conjuntos que, também, se adequam aos mesmos axiomas.

No que tange a Frege, contemporâneo, inspirador e, ao mesmo tempo, adversário de Russell, podemos dizer que sua influência foi de suma importância para o desenvolvimento da teoria lógico-matemática de nosso filósofo.

No mais, a obra de Russell, mesmo que tenha passado por críticas e autocríticas foi, é e sempre será um precioso objeto de estudo para os amantes e curiosos da Matemática. Do ponto de vista filosófico, o logicismo é um marco na Filosofia da Matemática e todo estudioso destes 
assuntos deve tentar compreender aquilo que o logicismo propõe e quais são as suas limitações. Nesse espírito, assim termina o livro Introdução à Filosofia da Matemática de Russell: “Se algum estudante for levado a um sério estudo da lógica matemática por este pequeno livro, este terá servido ao principal propósito com que foi escrito" (RUSSELL, 1966, p. 197). 
Referências

ABBGNANO, N. Dicionário de filosofia. São Paulo: Martins Fontes, 2003.

BOYER, B. História da matemática. 2. ed. São Paulo: Edgard Blucher Ltda., 2009.

BURGET, T. Belief de re. The Journal of Philosophy, n. 6, p. 356, 1977.

EVES, H. Introdução à história da matemática. Campinas: UNICAMP, 2004.

FERREIRA, I. L. A distinção analístico-sintético: um estudo comparativo entre Frege e Kant. 2007. 98 fl. Dissertação (Mestrado em Filosofia) — Pontifícia Universidade Católica de São Paulo, Programa de Pós-graduados em Filosofia, São Paulo.

FREGE, G. Os fundamentos da aritmética. In: Os Pensadores. São Paulo: Abril Cultura, 1980.

GOMES, N. G. Os progressos da filosofia no século XX. In: SIMON, S. (ORG.). Um Século de Conhecimento:Arte, Filosofia, Ciência e Tecnologia no século XX. Brasília: UnB, 2011. p. $795-871$.

GOMIDE, E. F. A matemática no século XX. In: SIMON, S. (ORG.). Um Século de Conhecimento:Arte, Filosofia, Ciência e Tecnologia no século XX. Brasília: UnB, 2011. p. 987-1014.

HAACK, S. Filosofia das lógicas. São Paulo: UNESP, 1998.

KENNEDY, H. Peanos̀ concept of number. In: Twelve Articles on Giuseppe

Peano. São Francisco: Peremptory Publications, 2002.

LIMA, G. F. Introdução à criptografia e ao código RSA. Revista do Departamento de Matemática da PUC-Rio, PUC-Rio, Rio de Janeiro, 2007. Disponível em: <http://www.mat.pucrio.br/arquivos/0405Hacon_Silva.pdf>. Acesso em: 5 fev. 2014.

ROSENTAL, M.; IUDIN, P. Diccionario filosofico. Havana: Editora Política, 1973.

RUFINO, M. Numbers and sets. Kriterion, Belo Horizonte, n. 104, p. 130-146, Dez. 2001.

RUSSELL, B. Introdução à filosofia da matemática. Rio de Janeiro: Zahar, 1966.

RUSSELL, B. História do pensamento ocidental. Rio de Janeiro: Ediouro, 2001. 